\title{
Effects of Greening on the Climate of Tama New Town
}

\author{
Vu Thanh Ca ${ }^{*}$ Takashi Asaeda † Takeshi Fujino ${ }^{\ddagger}$ \\ and Masahiro Murakami ${ }^{\S}$
}

\begin{abstract}
Observations were carried out to investigate effects of greening on the climate of Tama New Town. It was found that greening areas have significantly reduced the intensity of urban heat island in the town. Effects of greening on the urban heat island intensity was strongest at noon and in the early afternoon with the air temperature inside the Tama New Town Central Park was more than $2^{\circ} \mathrm{C}$ lower than that at the surrounding commercial or parking areas. Soon after sunset, temperature of the vegetated surface in the park became lower than that of the air and the park became a cool island. At the same time, paved asphalt or concrete surface in the town remained hotter than the atmosphere even at night. The upward sensible heat flux from the ground surface to the atmosphere together with anthropogenic heat made the air temperature in the town higher than that in the park.

A turbulent closure model had successfully simulated the heating and dynamical processes in the area. The simulation results revealed that evaporation from water and vegetated surface cooled down the surface in the park.
\end{abstract}

\section{Introduction}

It has been well-known that the development of cities has significantly changes the climate of the city and surrounding areas. The increase in the sealed portion of the ground surface in the urban area by pavement, road and buildings has significantly reduce the evaporation from the ground surface, and consequently increase the underground heat storage. This underground heat storage makes the ground surface temperature higher than that of the previous bare soil and vegetated surface, thus increase the sensible heat exchange between the ground surface and atmosphere and the upward long wave radiation. This together with anthropogenic heat released from industry and human activity makes the air temperature in the urban area significantly higher than that in the surrounding rural area, causing the so called urban heat island (Asaeda and Vu, 1993; Harazono et al, 1991).

Together with the process of urbanization, urban areas becomes wider and it is expected that the problem of urban heat island will become more serious in future. This will bring about significant affects on the well-being of urban residents. Thus some measurements must be taken to make the urban environment more comfortable for living.

It has been reported that greening areas in cities not only improve the urban landscape, but also can regulate the urban climate by increasing the moisture content in the air and reduce the urban air temperature (Harazono et al, 1991; Honjo and Takakura, 1991). This is due to the fact that with the present of vegetated surface, evaporation and evapotranspiration processes can transform a large portion of incoming solar radiation to the surface, which otherwise should

\footnotetext{
*Ph.D., Saitama University

${ }^{\dagger}$ Assoc. Prof., Saitama University

$\ddagger$ Graduate School, Saitama University

${ }^{\S}$ Nihon Koei Co.Ltd.
} 


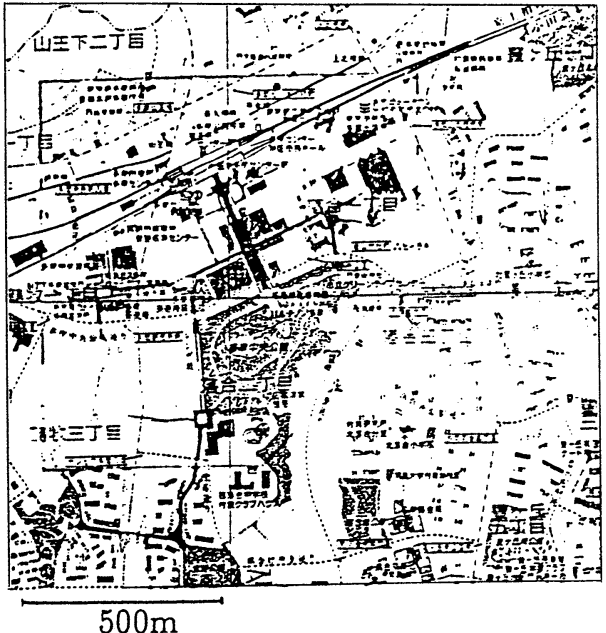

Fig. 1 Map of the study area

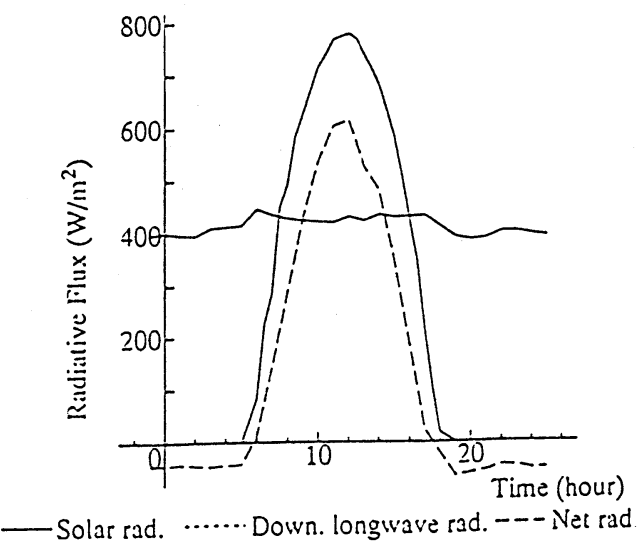

Fig. 2. Radiation data recorded at the grass surface

become the underground heat storage, into latent heat and makes the ground surface cooler. Thus to make a good plan for the development of a city, effects of greening on the urban thermal climate should be carefully studied. Despite the importance of the problem, there are still few studies about this subject.

The purpose of this study is to give a detailed investigation on the effects of greening areas on the thermal climate of a new city in the Tokyo Metropolitan area, the Tama New Town through field observations and numerical simulation.

\section{Observational Data}

The study area is inside Tama New Town, a new, well-planned city located in the West of the Tokyo Metropolitan area. The construction of the town was beginned by the year of 1963 . At present, the town has the area of $30.2 \mathrm{~km}^{2}$ with the population of about 410000 . The study area is near the Tama Center Station as depicted in Figure 1 with the size of about $1.2 \mathrm{~km} \times 1.2 \mathrm{~km}$. As shown in the figure, a large portion of the ground surface in the study region is covered by commercial and office buildings together with asphalt paved parking area. There are several greening areas in the region with the largest one as the Tama Central Park.

Observations were carried out during summer season from August to September 1994. During the observations, hourly values of air temperature, wind velocity, atmospheric relative humidity, leaf surface temperature, and temperatures of the grass surface, wall and pavement surface were measured at many locations in the area by six groups of students riding on bicycles and cars. Solar radiation, downward longwave radiation, net radiation, albedo together with soil temperature at the ground surface, $5 \mathrm{~cm}$ and $10 \mathrm{~cm}$ depth were measured at the center of a wide grass surface in the center of the park. Air temperature, relative humidity and wind velocity were also measured at the height of $112.6 \mathrm{~m}$ above the ground surface on the top of the Fukutake Publishing House building, which should be represented for the region. The obtained data of atmospheric temperature and wind velocity were confirmed by the data obtained from meteorological observational stations located in the Kanto area. Although observations were carried out for several times, in this paper, only results on fine days of August 26 and August 27 are reported.

The atmospheric conditions such as solar radiation, atmospheric downward longwave radiation, net downward radiation, relative humidity, air temperature and wind velocity recorded during the experiment at the grass surface are depicted in Figures 2 and 3. From the figures, it is clear that during the day, the weather was very fine with the maximum solar radiation flux reaching $780 \mathrm{~W} / \mathrm{m}^{2}$. The highest air temperature was $32.4^{\circ} \mathrm{C}$ and observed at $2 \mathrm{p} . \mathrm{m}$. while the lowest air temperature was $23.5^{\circ} \mathrm{C}$ and observed at 6 a.m.

Figure 4 depicts the time variation of the temperature of a asphalt paved surface in a parking 


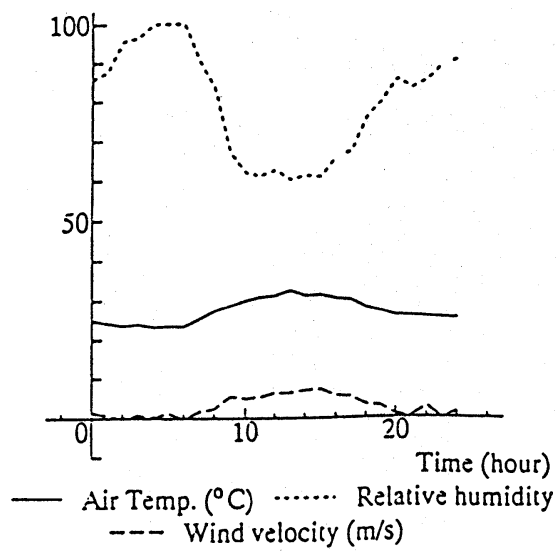

Fig. 3. Atmospheric temperature, soil surface temperature, relative humidity and wind velocity recorded at $1.5 \mathrm{~m}$ above the grass surface

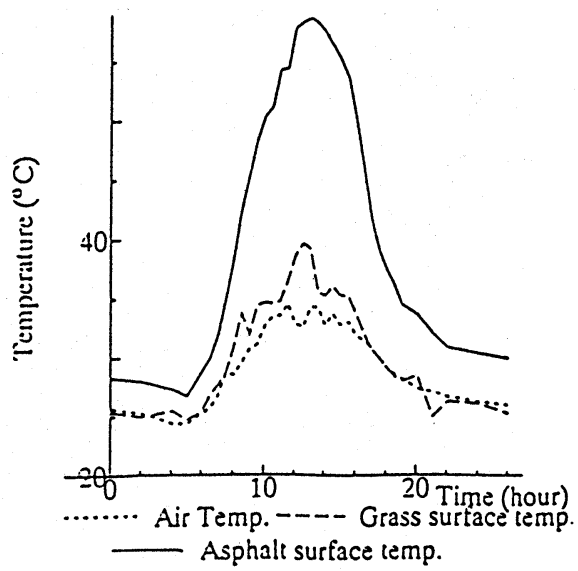

Fig. 4. Temperature of the surfaces and the air at a parking area

area together with the temperature of a nearby grass area and the air temperature measured at $1.5 \mathrm{~m}$ above the surface. As shown in the figure, temperature of the asphalt surface reached the highest value of $59^{\circ} \mathrm{C}$ at about 1 p.m.. Air temperature here reached the highest value of $34.5^{\circ} \mathrm{C}$ at 2 p.m., about $2^{\circ} \mathrm{C}$ greater than that above the grass surface inside the park. At the same time, temperature of the nearby grass surface reached the highest value of only $39.7^{\circ} \mathrm{C}$ at 1 p.m., almost $20^{\circ} \mathrm{C}$ lower than that of the asphalt surface. Time variation of the temperature of the grass surface inside the park (not shown) has the same pattern as that depicted in this figure. Thus it is expected that the sensible heat exchange between the asphalt surface with the atmosphere is much larger than that between the grass surface and the atmosphere. This is the reason that the highest air temperature at the parking area is about $2^{\circ} \mathrm{C}$ greater than that above the grass surface inside the park. In the afternoon, the temperature of the grass surface decreased very fast to the atmospheric temperature at about 6 p.m. and from 7 p.m. onwards, it was lower than the atmospheric temperature. Thus at night, the grass surface cooled the atmosphere. Throughout the day, temperature of the asphalt surface was always higher than that of the atmosphere, even at night and in the early morning and this surface always heated the atmosphere.

Figures $5(\mathrm{a}, \mathrm{b})$ depict the contour lines of the atmospheric temperature measured at 1.5 $\mathrm{m}$ above surface at $2 \mathrm{p} . \mathrm{m}$. and 8 p.m., respectively. The figures also indicate that there is a cooling area at the Tama Central Park and hot areas at the office or parking land with the difference between coolest and hottest air temperature of about $2^{\circ} \mathrm{C}$.

\section{$3 \quad$ Numerical Modelling}

A three-dimensional turbulent closure model was developed to simulate the dynamical and heating processes in the region. The main equations of the model obtained after applying the Reynolds average are as follows.

The equations governing physical processes in the atmosphere are the same as that of Melor and Yamada (1974) and Yamada (1982) as follows

Continuity equation

$$
\frac{\partial \rho}{\partial t}+\frac{\partial \rho U_{j}}{\partial x_{j}}=0
$$

Momentum equations

$$
\frac{\partial U_{i}}{\partial t}+U_{j} \frac{\partial U_{i}}{\partial x_{j}}+\varepsilon_{i k l} f_{k} U_{l}=\frac{\partial}{\partial x_{j}}\left(\overline{u_{j} u_{i}}\right)-\frac{1}{\rho} \frac{\partial P}{\partial x_{i}}+[1-\beta(\Theta-<\Theta>)] g_{i}+\nu \frac{\partial^{2} U_{i}}{\partial x_{j}^{2}}-\frac{\overline{\partial p}}{\partial x_{i}}+\nu \frac{\partial^{2} u_{i}}{\partial x_{k}^{2}}
$$




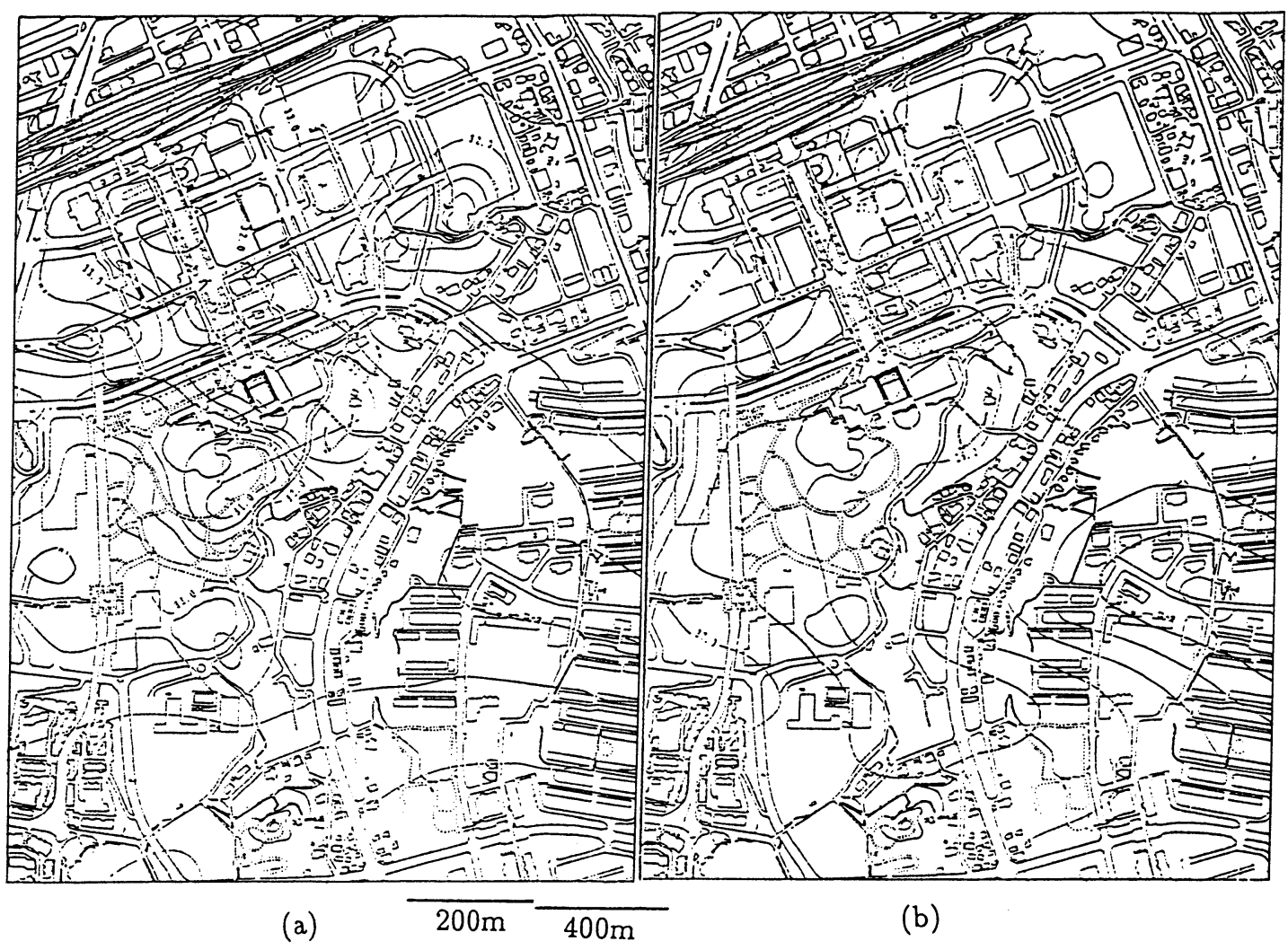

Fig. 5 Contour lines of atmospheric temperature at (a) 2 p.m. and (b) 8 p.m.

Equation of heat transfer in the atmosphere

$$
\frac{\partial \Theta}{\partial t}+U_{j} \frac{\partial \Theta}{\partial x_{j}}=-\frac{\partial}{\partial x_{j}}\left(-\overline{u_{j} \theta}\right)+\frac{1}{\rho C_{p}} \frac{\partial R_{n}}{\partial z}
$$

Equation of moisture transfer in the atmosphere

$$
\frac{\partial Q}{\partial t}+U_{j} \frac{\partial Q}{\partial x_{j}}=-\frac{\partial}{\partial x_{j}}\left(-\overline{u_{j} q}\right)
$$

where $U_{i}, u_{i}, \Theta, \theta$ and $Q, q$ are the average and fluctuating components of the wind velocity in the $i$-direction, atmospheric temperature and water vapor mixing ratio, respectively; $t$ the time; $x_{i}$ the co-ordinate in the $i$ th-direction; $\rho$ air density; $P$ pressure; $g_{i}$ the $i$ th component of the gravity vector; $C_{p}$ the specific heat of air at constant pressure; $R_{n}$ the short and longwave radiation flux; $f_{k}$ the Coriolis parameter; $\varepsilon_{i k l}$ the alternation tensor; $<>$ denotes the average over a horizontal plane and the overbar denotes ensemble average. The last two terms in equation (2) represent the form drag force exerting on the wind field due to the present of surface structures such as building or trees.

A turbulent kinetic energy equation is given by

$$
\frac{\partial k^{2}}{\partial t}+U_{j} \frac{\partial k^{2}}{\partial x_{j}}-\frac{\partial}{\partial x_{k}}\left[l k S_{k} \frac{\partial k^{2}}{\partial x_{k}}\right]=2\left(P_{s}+P_{b}-\varepsilon\right),
$$

An equation for turbulent length scale 


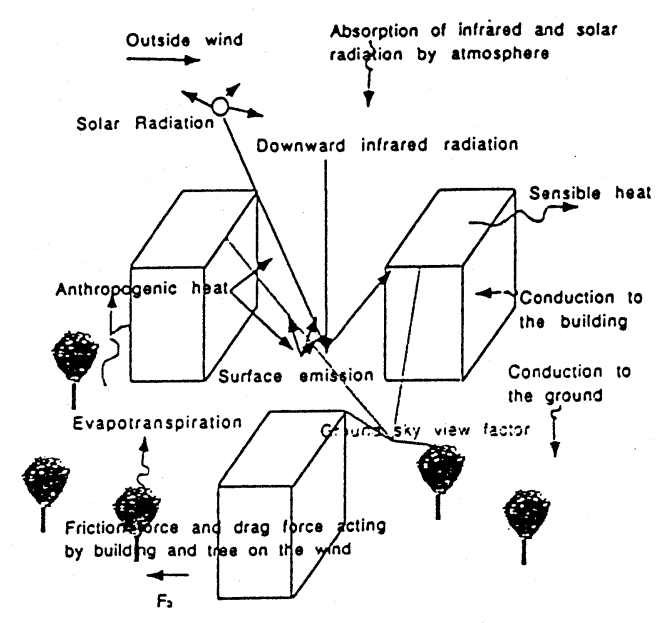

Fig. 6 Sketch of the lower boundary conditions for the numerical model

$$
\frac{\partial k^{2} l}{\partial t}+U_{j} \frac{\partial k^{2} l}{\partial x_{j}}-\frac{\partial}{\partial x_{k}}\left[l k S_{k} \frac{\partial k^{2} l}{\partial x_{k}}\right]=l E_{1}\left(P_{s}+P_{b}\right)-\frac{k^{3}}{B_{1}}\left[1+E_{2}(l / K z)^{2}\right] .
$$

The lower boundary conditions for equations (1-6) for the urban area are very complicated due to the present of urban structures. A model for the urban climate should be able to account for the influence of these factors. In this model, for the canopy, the drag force acting by the tree or building on the wind field is evaluated as

$$
\frac{\overline{\partial p}}{\partial x_{i}}=C_{d} a(z) U_{i}\left|U_{i}\right|
$$

For the forest canopy, $a(z)$ is the leaf area density and the drag coefficient is considered constant $(=0.2)$ (Yamada, 1982). For the building canopy, $a(z)$ is the projected area of the building on the wind direction in one unit volume and the drag coefficient is evaluated as (Maruyama and Ishizaki, 1989)

$$
C_{d}=\frac{\left(164 \rho_{r}+16\right) U_{*}}{\left|U_{i}\right|}
$$

where $U_{*}$ is the frictional velocity inside the canopy.

A one-dimensional heat conduction equation is solved to get the temperature distribution in the ground, and inside the roof and walls of building with the outside-air-contacted surface boundary conditions as

$$
-K \frac{\partial T_{c}}{\partial z_{s}}=R_{n e t}+H+L E
$$

where $R_{n e t}$ is the net radiation to the surface, $H$ the sensible heat flux and $L E$ latent heat flux. The net radiation to a point on the surface is the sum of direct and diffused solar radiations, shortwave reflection and longwave emission from the surrounding environment and longwave radiation from the sky minus the emission from the surface and can be expressed as

$$
R_{n e t}=\left(S+s \psi_{s k y \rightarrow A}\right)\left(1-\alpha_{A}\right)+R_{a} \psi_{s k y \rightarrow A}+\sum_{i}\left(S_{i}+s_{i} \psi_{s k y \rightarrow i}\right) \alpha_{i} \psi_{i \rightarrow A}+\sum_{i} R_{i} \psi_{i \rightarrow A}-\varepsilon \sigma T_{A}^{4}
$$




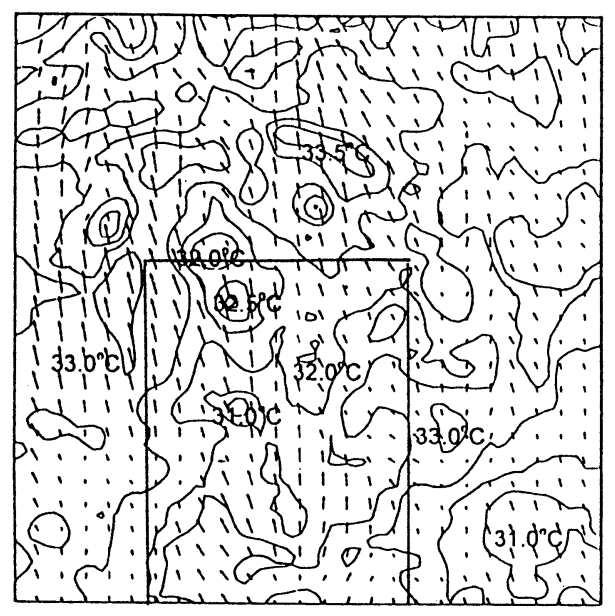

$500 \mathrm{~m}$

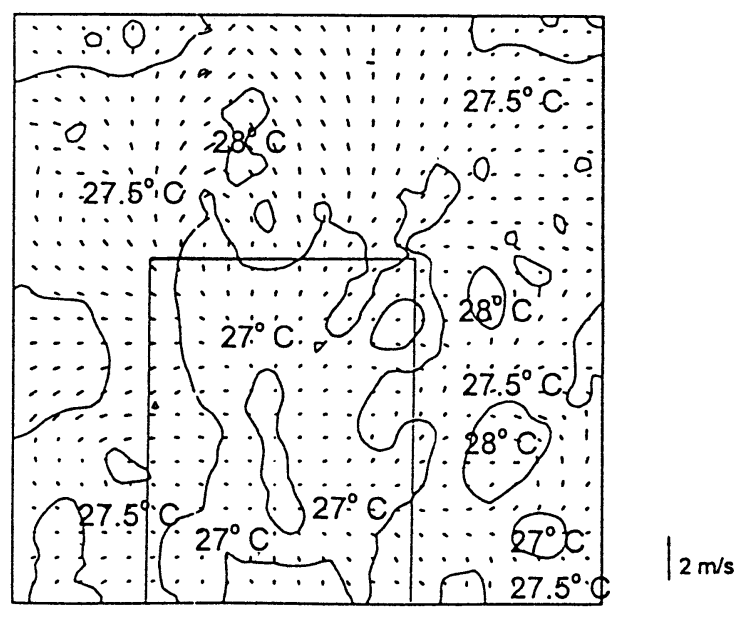

(b)

(a)

Fig. 7 Computed atmospheric temperature and wind velocity at (a) 2 p.m. and (b) 8 p.m.

A sketch of the lower boundary conditions for the model is depicted in Figure 6.

Figure $7(\mathrm{a}, \mathrm{b})$ depicts the computed air temperature and wind field at $2 \mathrm{~m}$ above the computational region at 2 p.m. and 8 p.m., respectively. The observational area is the area inside the box in these figures. By comparing results in these figures with the observed air temperature distributions depicted in Figures $5(\mathrm{a}, \mathrm{b})$, it can be stated that the model can simulate the heating processes in the region successfully. Results of computations showed that at noon, the latent heat flux from the grass surface reached $450 \mathrm{~W} / \mathrm{m}^{2}$ and this was the main reason that makes temperature of the grass surface much lower than that of the asphalt pavement surface.

\section{References}

Asaeda T., and V.T. Ca (1993) The subsurface transport of heat and moisture and its effects on the environment: a numerical model. Boundary-Layer Meteorol. 65, 159-179.

Harazono Y., S. Teraoka, I. Nakase and H. Ikeda (1991) Effects of rooftop vegetation using artificial substrates on the urban climate and the thermal load of buildings. Energy and Buildings 15-16 435-442.

Honjo T. and T. Takakura (1991) Simulation of thermal effects of urban green area on their surrounding areas. Energy and Buildings 15-16 443-446.

Maruyama T. and Ishizaki H. (1989) Experimental study on the vertical distribution of time and space average wind velocity in the urban canopy. Proc. Japan Soc. Arch. Eng. Sym. 60-65. (in Japanese)

Mellor G.L. and T. Yamada (1974) A Hierarchy of turbulence closure models for planetary boundary layers. J. Atmos. Sci. 31 1791-1806.

Mellor G.L. and T. Yamada (1982) Development of a turbulent closure model for geophysical fluid problems. Rev. Geophys. Space Phys., 20, 851- 875. 